\title{
L1 thinking-for-Speaking Habits are Difficult to Change in L2: Evidence from the Semantic Domain of Motion
}

\author{
Imed Louhichi \\ Language \& Literature \\ American University of Ras Al Khaimah \\ Ras Al Khaimah, United Arab Emirates
}

\section{Theoretical Background}

Research into how a universal semantic domain like motion is narrated differently by speakers of typologically different languages (i.e., SATELLITE-FRAMED and VERB-FRAMED) led Slobin (1996a, 1996b, 2000, 2014) and his colleagues (Berman and Slobin, 2004) to make informed predictions about the influence of grammatical categories on the learning of first languages (L1) and second languages (L2):

(a) Language-induced thoughts are determined by the typological characteristic of L1 (Slobin, 1996a, p. 89).

(b) Language induced-thought processes develop into habits of thinking-for-speaking (TfS) (Slobin, 1996a, p. 89).

(c) L1 TfS habits are difficult to change whena typologically distinct L2 is learned in adulthood (Slobin, 1996a, p. 89)

Research into how motion events are expressed in different languages lent support to predictions (a) and (b) (e.g., Ibarretxe-Antuñano, 2004;Cifuentez-Férez\&Gentner, 2006;Slobin, Ibarretxe-Antuñano, Kopecka, \&Majid, 2014;Feist, 2015; Özçalişkan, 2015). However, research into the validity of prediction (c) has so far delivered mixed results. As such, while some limit L1 influence to beginner and intermediate levels (e.g., Cadierno\& Ruiz, 2004; Cadierno, 2010; Song et al., 2016), others have extended this influence to advanced levels as well (e.g., Stam, 2010; Alonso, 2011; Larrañaga, Treffers-Dallers, Tidball, \& Ortega, 2011).

These TfSfindings have direct bearings on the notion of 'frequency' - a theoretical construct that is often recruited by usage-based and connectionist theories to explain ultimate attainment in both L1 and L2 acquisition (Slabakova, 2015, p.680; Paquot, 2017, p. 28). A fundamental assumption behind this construct is that whenever L2 learners are exposed to target language (TL) constructions with sufficient frequency, successful learning takes place. Importantly, while Ellis (2002) remarks that frequency is not the only determining factor in second/foreign language acquisition (SLA), he asserts that SLA research can no longer afford to ignore the role of frequency in language learning as "there is now ample justification for its reinstatement as an all-pervasive causal factor" (2002, p. 178). According to Ellis, this conclusion is supported by a wide range of evidence that "shows how language processing is intimately tuned to input frequency (2002, p. 143).

Recent research results on the role of frequency in SLA have offered confirmation as well as challenges to the causal relationship between ultimate attainment and the input frequency. For instance, Collins, Trofimovich, White, Cardoso, \& Horst (2009) set out to determine whether it is possible to identify 'difficult' and 'easy' constructions for L2 learners. Using a corpus of 110,000 words of instructional talk to L2 learners, they analyzed three English structures (i.e., the simple past, possessive determiners 'his/her', and the progressive aspect). The results corroborated the premise that input frequency is decisive in the successful learning of TL constructions. They concluded that manipulating instructional input is needed to help learners notice constructions that prove more opaque than alternative ones (p. 329). Similarly, in response to Ellis's seminal article on frequency in L2 learning, Gass and Mackey argue thatthe pervasivess of frequency surfaces "in several areas of second language acquisition, including interactional input and output and speech processing" (2002, p. 249). However, they also point out that there are many grammatical properties and constructions where L2 acquisition appears to develop along its own course and at its own rate, regardless of the input frequency (p. 249). Equally, following an investigation of the acquisition of topicalization by Spanish learners of English, Slabakova (2015, p. 695) concludes that "just encountering dislocated constructions [...] is not sufficient for acquisition: the learner needs to observe and evaluate the wider context and the construction's function within that context."

In brief, on the one handSlobin (1996a, p. 89) claims language induced-thought processes develop into habits of TfS and, in turn, these habits become difficult to change in adult L2 acquisition. On the other hand, the input frequency hypothesis (IFH) claims the more frequent a construction is the more optimal learning takes place. Because these predictions make opposing claims about language learning, we contend they may be profitably investigated to 
understand issues of ultimate attainment in SLA. Accordingly, we select the linguistic description of motion events in English and Tunisian Arabic (TA) to test these predictions because the semantic domain ofmotion is both universal and yet language-specific (Talmy, 2000). It is pevasive in human conceptualization (Loucks and Pederson 2011) and in interaction (Slobin, 2004). Most importantly, constructions which are used for the expression of motiontend to be "colloquial in style, rather than literary, stilted," "frequent in occurrence in speech, rather than only occasional", and "pervasive, rather than limited, that is, a wide range of semantic notions are expressed in this type" (Talmy, 1985, p. $63)$.

The outline to the remainder of this article is as follows. First, we explain our analytical background by describing the standing of TA in the typology of motion event description (Section 2.1), the boundary-crossing constraint (Section 2.2), and the description of boundary-crossing in TA (Section 2.3). In Section 3 and Section 4, we describe our methodology and results, respectively. To anticipate, our data shows thatL2 English learners differ from L1 English speakers in how they observe the boundary-crossing constraint. With the exception of one participant whose profile is distinctive, these advanced L2 English learners have not moved in the direction of English lexicalization biases from the patterns typical of their L1. In Section 5 and 6, we summarize and discuss the implications of our findings for instructed second language learning. We build on two different but complementary proposals in order to explain possible reasons why the learning of [manner + out] constructions may not easily obtain for the L2 learners of English whose L1 is V-framed. We share our conclusions in Section 7 and state some limitations to this study and guidance for future research in Section 8.

\section{Analytical Background}

\subsection{The typology of motion event description}

In a landmark article, Talmy (1985) has proposed a binary typology based on where in a motion event the semantic meanings PATH versus MANNERare conflated. If the semantic meaning path conflates with that of MOTION in the main verb, then this language is VERB-FRAMED(V-language). However, if path is encoded on a SATELLITE that accompanies the main verb (e.g., up, out, across), then this language is SATELLITE-FRAMED (S-language). Figure 1captures this typology concerning English as an S-framed language (Talmy, 2000) and Tunisian Arabic (TA) as a V-framed language (Louhichi, 2018). It shows that the semantic component manner is encoded in the main verb in English. However, in TA it is encoded in an adjunct. This conflation pattern is significant because a semantic notion that is characteristically encoded in an obligatory constituent of a clause (i.e., a verb) should encourage its speakers to attend to and express manner of motion more frequently (Slobin, 1996b). On the contrary, when manner is encoded in optional constituents of a clause (e.g., adjuncts and subordinate clauses), speakers of this language attend to and express manner of motion only when manner is critical to the message being delivered. As the next section shows, this 'grammatical determinism' - or habits of 'thinking-for-Speaking' as Slobin (1996b) calls it - is especially evident in boundary-crossing situations.

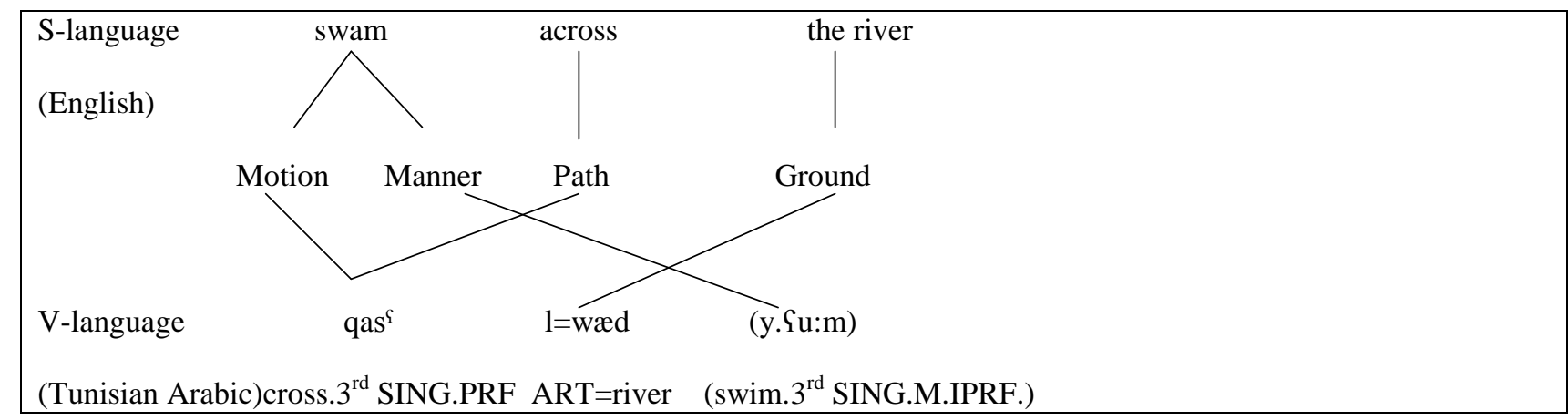

Figure 1: Mapping patterns between the conceptual components of motion events and parts-of-speech in S-framed and V-framed languages (Adapted from Zlatev, Blomberg, \& David, 2010, p. 390).

\subsection{The boundary-crossing constraint}

Slobin\&Hoiting (1994) argue that V-languages do not favor the use of manner verbs as main verbs when a spatial boundary is crossed. For instance, a motion event where an owl pops out of a hole in a tree involves the crossing a boundary between 'in' and 'out' of the hole. In this event, English speakers are reported to say 'the owl flew out of the hole,' while speakers of a V-language like Spanish avoid describing the crossing of the boundary. Instead, the tendency is to say the equivalent of 'The owl flew from the tree' assumingly because boundary-crossing implies a change of state while manner verbs are activity verbs (Slobin and Hoiting, 1994). 
Consequently, unless manner verbs depict an "instantaneous" act, manner verbs cannot readily be used to describe the crossing of spatial boundaries. As Slobin (2004, p. 226) states, in V-languages "one can 'throw oneself into a room,' but one can't generally "walk into a room"'. In brief, it is generally accepted that V-language speakers use path constructions of the type [Path Verb + from] (henceforth $\left[\mathrm{V}_{\mathrm{P}}+\right.$ from]) to describe boundary-crossing events while Sframed languages use manner constructions of the type [Manner Verb + out] (henceforth $\left[\mathrm{V}_{\mathrm{M}}+\right.$ out](e.g., Alonso, 2011; Feist, 2015; Song et al. 2015; Özçalişkan, 2015).As the following section shows, TA speakers adhere to the Vframed TfS norm.

\subsection{The description of boundary-crossing in Tunisian Arabic}

TA is spoken in Tunisia - a North African country. Following an analysis of 15 narratives, Louhichi (2018) concludes that TA belongs to the V-framed group. Louhichi (2018) provides two main justifications for this classification. First, TA speakers have lexicalized the semantic meaning path in main verbs. Second, when describing boundary-crossing situations, the participants have rarely used manner verbs in single clauses as satellite language speakers typically do (Slobin, 1996a, Talmy, 2000). Importantly, Louhichi (2018) cautions that the mere labeling of this language as Vframed overlooks several linguistic means that set this language apart from typical V-framed languages like Spanish. As such, the participants have used 28 manner verbs to describe various events across the narrative as compared to 17 path verbs. ${ }^{1}$ Additionally, although the boundary-crossing constraint seems to influence attention to manner at the clause level, the participants have expressed manner meanings using a chain of clauses describing a cause-and-effect association between the sub-events that make up an entire boundary-crossing scene. Participants have achieved this syndetically by using overt coordinating conjunctions as in (1), and asyndetically (no overt coordinating conjunction) as in (2)a and (2)b:
Ij=jrana hawni doebbit
$m i=l=w a h d a \quad w \quad$ faș $3 i t$
$\mathrm{ART}=$ frog there jump.PF.3F from=ART=thing and escape.PF.3F
'Thefrogjumpedoutofthatthingandranoff' (Louhichi 2015, p. 99)

(2)

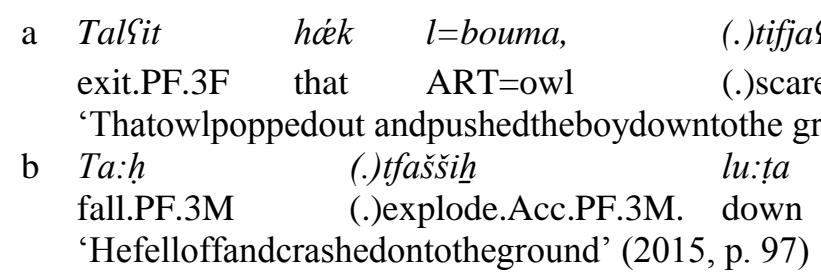

In brief, the findings of this typological study offer optimal grounds for testing Slobin's predictions for the influence of L1 TfS habits on the learning of those of the speakers of a typologically opposing language, and the assumption that ample exposure to TL constructions optimizes the learning of these constructions.

\section{Methodology}

\subsection{The participants}

We have recruited 26 participants in total: Thirteen native speakers of English (mean age 39.84), and thirteen 'advanced' L2 speakers of English whose L1 is T.A (mean age 38.42). We use the label 'advanced L2 speakers' as opposed to 'advanced L2 learners' of English because the latter term suggests participants are still enrolled in language programs. This is the case of the participants in Wu (2010), Ekiert (2010), Larrañaga et al. (2011), and Alonso (2011).

\footnotetext{
${ }^{1}$ An anonymous reviewer has rightly pointed out that a rationale for the categorization of motion verbs by Louhichi (2018) is needed to assess the validity of the conclusion that TA is a V-framed language. This is a valid point given that the categorization of motion verbs is generally characterized as problematic (e.g., Caballero, 2007, p. 2101; Ibarretxe-Antuñano, 2004, p. 322; Levin, 1993, p. 15, Zlatev\&Yanglang, 2004, p. 162). Although Louhichi (2018) does not explicitly discuss what path and manner verbs are, he considers path verbs to depict "general direction of movement in space (e.g., returning, crossing, arriving, reaching a destination, catching up with someone." As far as manner verbs are concerned, Louhichi (2018, p. 352) draws a distinction between verbs which have basic manner meanings (e.g., verbs of walking, 'jumping,' 'running,' 'escaping,' 'flying,' 'stopping,' and 'climbing') and verbs which have fine-grained manner meanings that reflect a token/type relationship (e.g., zriff and zriggfor 'sneak out in a speedy manner' and 'pop out suddenly.'
} 
However, our L2 participants are all university instructors who hold postgraduate degrees in English-related majors (see Appendix 1). We contend that our study group and our controlled are well matched for this study. Our controlled group consists of thirteen British native speakers from the Brighton area (see Appendix 2). They have differentpersonal and professional profiles because we wanted to ensure variables like gender, age, and occupation cancel each other out in the activity of narrating a story in British English. We reasoned that a randomized sample should providea reliable picture about the TfS norms of native speakers of English.

\subsection{Instruments and procedure}

Following Berman and Slobin (1994), we have used a children storybook to elicit our data. 'Frog, where are you?' (Myers, 1959) is a collection of 32 wordless pictures of a boy, his dog, and his pet frog. The frog goes missing overnight and the entire story depicts the boy and his dog going on a search journey to find the frog. To elicit our data, first, we ask our participant to look at the entire collection of pictures so that they work out the plot. Then, we record the narratives as they narrate the story picture by picture.

\subsection{Coding}

To transcribe and code the narratives, we use theclauseastheminimumunitof analysis. Thisisdefinedby SlobinandBerman(1994)as"anyunit containing a unified predication, whetherintheformofaverboradjective"(1994, p.26).Inthissense, running through thewoods, theywerescared,wanttoclimbthetreeall areclauses.Accordingtotheauthors,clauses makeitpossibletoassess howmanypredicationsarepacked togetherinasingleeventinthedifferentnarratives. This is an essential variable in deciding whether the assumed boundarycrossing constraint influences speakers. To explain a little, consider a typical response of an English native speaker (3)a and that of a TA speaker cited in 1 and reproduced in (3)b for illustration:

(3) a The frog jumped out of the jar

b Ij=jrana hawni doebbit mi=l=wahl.a $\quad W \quad$ faș3it

$\mathrm{ART}=$ frog there jump.PF.3F from=ART=thing.F and escape.PF.3F

'Thefrogjumpedoutofthatthingandranoff' (Louhichi 2015, p. 99)

According to Talmy's motion event typology and Slobin's account, (3)a is a single clause whose main verb conflates manner with motion (i.e., move in a jumping manner) and the satellite 'out' expresses the followed path, namely: the crossing of a three-dimensional space (i.e., the jar). However, although in (3)b the verb dcebb jumped'conflates manner with motion, the crossing of the boundary is not explicitly expressed in the preposition min 'from.' The crossing of the boundary is recovered inductively from the context, the resultative verbal clause fașit 'escaped.' Consequently, what we are interested in here is not whether the L2 participants can express manner meanings in general, but rather whether they can do so using a single clause to simultaneously describe the motion and manner of a figure from inside a three-dimensional space to its exterior.

To code our data we had to decide on the categorization of manner versus path verbs. As stated in footnote 1 , the literature on this topic is replete with controversy. However, in this study we follow Gruber (1967, p. 940), Talmy (1996, p. 221), and Slobin (2009, p. 219) in considering any English verb that concatenates with the satellite 'out' as a motion verb. This categorization overlooks the distinction between physical and metaphorical motion. Verbs of physical motion like 'come,' 'go,' and 'run' are considered as much of motion verbs as verbs of sound emission like 'shout' and verbs of vision like 'look'. To be selected, these verbs must necessarily concatenate with the English directional satellite 'out' to express the crossing of some form of a physical or a metaphorical boundary. To elaborate a little, Gruber (1967, p. 640) uses examplesin (4) to show that English verbs of vision (e.g., 'see' and 'look') concatenate with all the directional prepositions that typical motion verbs like 'fly' use: ${ }^{2}$

(4) a. Bill thought he could seeinto the room.

b. Thefrightenedbirdflewinto/over/through/behindthebush. ${ }^{3}$

The final step in coding our data relates to subject and data IDs. Following Berman and Slobin (1994), we useoneID code for theparticipantand another fortheclause. TheprefixoftheIDconsistsofthreeelementsand specifiesthesubjectID(e.g., A,B,C),nationality,andgender.Thedataportionof the ID specifies the utterance number and the pictures/ heisdescribing.

\footnotetext{
${ }^{2}$ Due to spaceconstraints, it is not possible to discuss this categorization any further here. However, Louhichi (2019) (forthcoming) discusses this theoretical framework extensively.

${ }^{3}$ Bold and Italics are added for emphasis. 
To illustrate, a code like [M-T-M/16-02] informs that theparticipant isidentifiedas [M], a [T]unisian,and[M]ale. The slant line introduces the data portion. It informs thattheutteranceisnumber 16 in the narrative and that itdescribes the eventsinpicture2ofthefrogstory (see Appendices 3 and 4 for further illustrations).

\subsection{Data Analysis}

Although the collected data covers the entire events of the story, we focus our analysis on three boundary-crossing scenesonly. We give the following rationale for this decision.First, as we have pointed out in Section 1.2, V-framed and S-framed languages sit on opposing poles when it comes to the linguistic means each uses to describe boundarycrossing events (i.e., [path/ manner verb + from] as opposed to [manner verb + out]). To address our research question, we reasoned it is sufficient to focus on motion events that capitalize on the use of 'out'.Second, in the spirit of the prototype theory of concepts (Rosch and Mervis, 1976), we assume that categories have graded structures, with some members being better exemplars than others are. Consequently, we have selectedthree boundary-crossing scenes that vary in terms of how prominent the crossing of a boundary is. ${ }^{4}$ We hypothesize that preferred modes of motion event descriptions should transcend prototypicality effects if grammatical structures have deterministic effects on TfS habits: ${ }^{5}$

\section{a. The jar scene ${ }^{6}$}

This scene is about pictures 2 and 3 of the frog story. We consider this scene to be the most typical boundary-crossing scene because it is explicit about the crossing of a boundary.As such, picture 2 shows the frog with one leg in and one leg out of a lid-less jar in which it is kept overnight. Picture 3 shows an empty jar suggesting the frog has escaped.

\section{b. The owl scene ${ }^{7}$}

This scene is about pictures 13 and 14 of the story. The boy is first pictured sitting on a tree branch looking into a hole when an owl pops out and scares the boy off. Because the owl merely appears to the boy, it is interesting to see whether the L1 and the L2 participants equally escort the owl beyond the boundary of the hole or stop at its opening. Recall that Louhichi (2015) reports the former to be the preferred TfS mode of native speakers of TA while Berman and Slobin (1996b, 2004) report the latter to be a typical TfS response of English narrators.

\section{c. The window scene ${ }^{8}$}

Because the crossing of the boundary in this scene is not evident, this scene may be considered the least typical. Picture 5 depicts the dog standing on a window ledge. Next, picture 6 shows the dog to be losing its balance and to fall to the ground due to a massive bowl stuck to its head. The central question here is whether the test group and the controlled group describe the motion in question as having started from within the inner boundary of the window or at/by its boundary (i.e., the window ledge). As example (5) shows, TA speakers expressthe onset of motion using the preposition min 'from' which is indeterminate about whether a boundary is being crossed or not. Consequently, Louhichi(2015, p. 88) points out that the core meaning of min 'from' may translate to both the English 'out of', or 'off':

$$
\begin{aligned}
& \text { (5) Ta: } \hbar \text { si l=kelb miš=šubbask luṭa } \\
& \text { Fall.PF.3M } \mathrm{Mr} \quad \mathrm{ART}=\mathrm{do} \quad \text { from=ART=windo to=down } \\
& \text { 'Mr.Dogfellwiththe bottleoutofthewindowdown(into/onto...)' [F-T-37-M/46-06] }
\end{aligned}
$$

\section{Findings}

Primarily, the expression of boundary crossing in English is expressed through the concatenation of verbs and the spatial particle 'out'. A frequency count of the morpheme 'out' across the entire 26 frog stories confirms that they form part of both the L1-English and the L2-English participants' active lexicon.

\footnotetext{
${ }^{4}$ To the best of our knowledge, previous work on the expression of boundary-crossing events has always assumed a classical approach to boundary-crossing events (i.e., necessary and sufficient conditions of membership). However, as our data shows, boundary-crossing situations are best categorized in terms of family resemblance and hence why we consider the jar scene to be the most prototypical of all the boundary-crossing scenes in the story.

${ }^{5}$ We have sought authorization to use the pictures. We have had no affirmative reply yet. We assume it is possible to point to MARIÑA TRIGAS as the website that hosts the images under investigation.

${ }^{6}$ The jar scene: https://goo.gl/images/6dt8DS

${ }^{7}$ The window scene: https://goo.gl/images/RjnBii

${ }^{8}$ The owl scene: https://goo.gl/images/ykkgdZ
} 
Precisely, in a total of 1068 clauses for the L2 narratives and 953 clauses for the L1 narratives 'out' surfaced 66 times in the L2 data as compared to 60 times in that of the L1. However, when it came to describing the three scenes under investigation, L1-English speakers showed an overwhelming preference for $\left[\mathrm{V}_{\mathrm{M}}+\right.$ out $]$ over $\left[\mathrm{V}_{\mathrm{P}}+\right.$ from $]$ constructions across the three scenes and the opposite is true for the L2 participants. Figure 2 summarizes these findings. Appendix 3 and Appendix 4 illustrate these contrasting styles in the description of the jar scene.

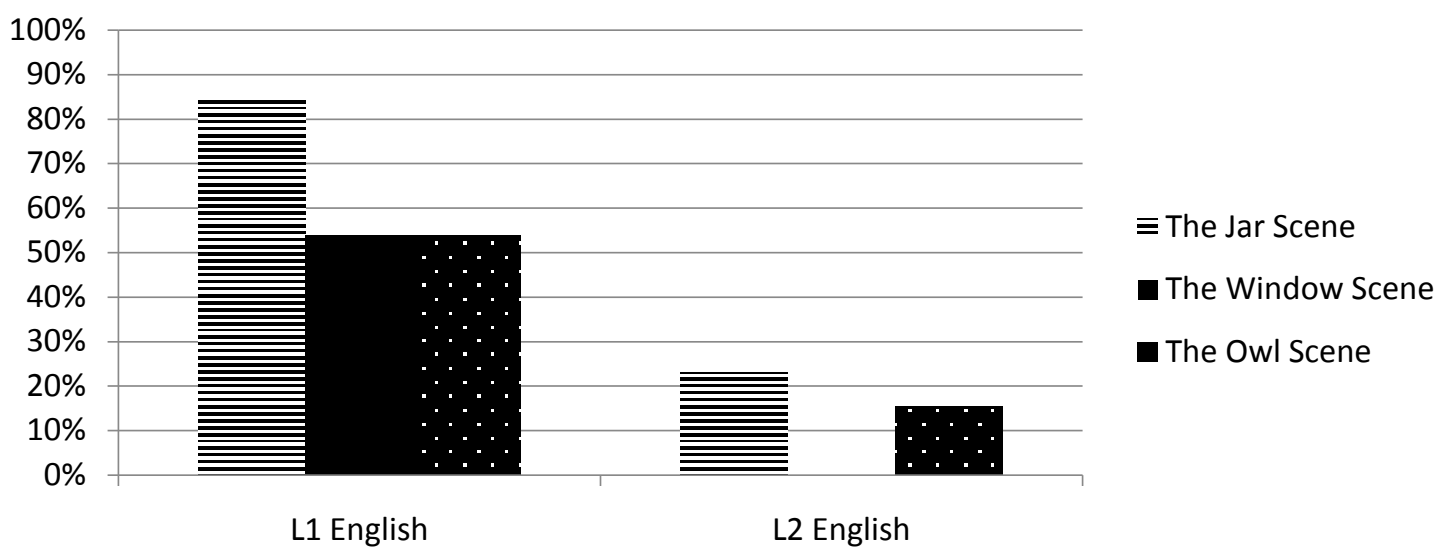

Figure 2: A comparisonof [VM + out] constructions in the $L 1$ and $L 2$ narratives

To determine whether the differences in the use of $\left[\mathrm{V}_{\mathrm{M}}+\right.$ out $]$ constructions are significant we use a multivariate analysis of variance (MANOVA). The aim is to test if there is an overall difference between the test group and the controlled group as well as differences in each scene concerning each group's mean manner constructions. The Pillai's Trace estimate corroborates our proposal that there is a main difference between the two groups across all the scenes $(\mathrm{V}=.55, \mathrm{~F}(3,22)=9.25, \mathrm{p}<.00)$. A comparison of the groups' responses for each scene, reveals a similar pattern in each case. L1 speakers have utilized more $\left[\mathrm{V}_{\mathrm{M}}+\right.$ out] constructions in the jar scene $(\mathrm{F}(1,24)=14.76, \mathrm{p}<.00)$, in the window scene $(\mathrm{F}(1,24)=14.00, \mathrm{p}<.00)$, and in the owl scene $(\mathrm{F}(1,24)=4.69, \mathrm{p}=.04)$.

At this point, the question that lends itself some significance is whether atrade-off between $\left[\mathrm{V}_{\mathrm{M}}+\right.$ out $]$ versus $\left[\mathrm{V}_{\mathrm{P}}+\right.$ out] constructions is bound to happen when speakers select one construction type rather than the other. More precisely, do L1 and L2 speakers opt for $\left[\mathrm{V}_{\mathrm{P}}+\right.$ out $]$ constructions when $\left[\mathrm{V}_{\mathrm{M}}+\right.$ out $]$ constructions have not been selected given that the spatial particle out is crucial to the expression of boundary-crossing in English? To address this question, Figure 3 compares the total number of $\left[\mathrm{V}_{\mathrm{P}}+\right.$ out $]$ constructions used by the $\mathrm{L} 1$ and the $\mathrm{L} 2$ participants in each of the three scenes. It points to interesting conclusions. Not only have the test group and the controlled group performed differently with respect to $\left[\mathrm{V}_{\mathrm{P}}+\right.$ out] constructions overall, but more importantly, favoring path constructions over manner constructions seems to vary in accordance with scene types. As such, six L2 participants used [ $V_{P}+$ out] constructions in the jar scene, but fewer in the window scene, and none in the owl scene. As for the L1 participants,three cases have been recorded in the owl scene, but none in the other two scenes. The alternative is to use a manner verb with a satellite that is not explicit about the crossing of the boundary (e.g., off).

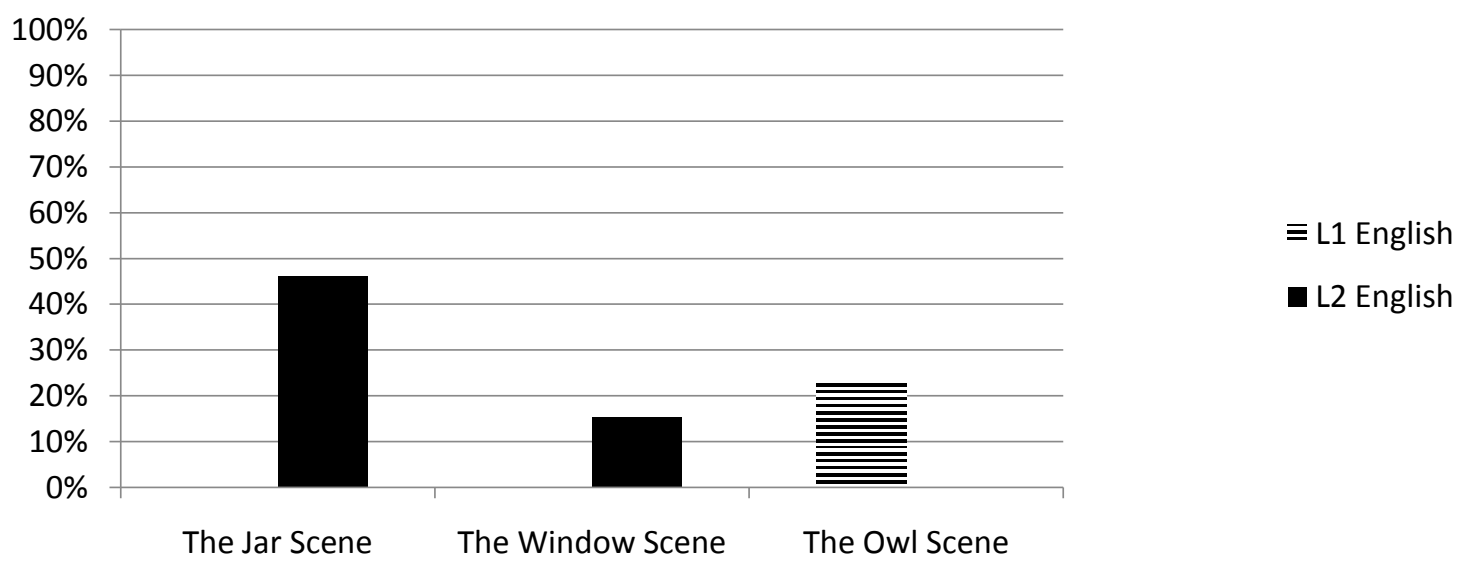

Figure 3: A comparison of [VP + out] constructions in the L1 and L2 responses 
Crucially, a MANOVA analysis shows an overall difference between L1 and L2 speakers in the way they use [ $\mathrm{V}_{\mathrm{P}}+$ out] constructions: $(\mathrm{V}=.30, \mathrm{~F}(2,23)=10.26, \mathrm{p}<.00)$. While in the jar scene L2 speakers have produced more path constructions than $\mathrm{L} 1$ speakers have $(\mathrm{F}(1,24)=10.28, \mathrm{p}<.00)$, no significant difference was noted in the owl scene (i.e., $(\mathrm{F}(1,24)=.23, \mathrm{p}=.64))$. In the window scene, a MANOVA analysis was not possible, however, since none of the groups produced any $\left[\mathrm{V}_{\mathrm{P}}+\right.$ out $]$ construction. ${ }^{9}$

\section{Summary}

In this study, we set out to test two opposing predictions about the influence of L1 on L2 learning. First, L1 speakers develop TfS habits that may prove difficult to change in adult second language learning (Slobin, 1996a). Second, that the frequent exposure to a target language construction facilitates learning (e.g., Ellis and Ferreira-Junior, 2009).The findings we have reported on in this paper show that L1 English speakers prefer $\left[\mathrm{V}_{\mathrm{M}}+\right.$ out] constructions when describing typicalboundary-crossing scenes, but less so in scenes that project a fuzzy picture about the crossing of a boundary. However, the L2 participants whose first language is TA show a clear preference for $\left[\mathrm{V}_{\mathrm{P}}+\right.$ out] constructions even in the most typical boundary-crossing scenes. In prototypical boundary-crossing scenes, a trade-off between $\left[\mathrm{V}_{\mathrm{M}}+\right.$ out $]$ versus $\left[\mathrm{V}_{\mathrm{P}}+\right.$ out $]$ obtains in $\mathrm{L} 2$ narratives but not in those of the L1 respondents. L2 respondents have complied with the boundary-crossing constraint of their L1 in that they have always opted for [ $\mathrm{V}_{\mathrm{P}}+$ out] constructions. To a certain extent, this finding supports what has been reported in Cadierno(2010, p. 22), namely: L2 speakers tend to overuse generic motion verbs like 'go' to describe all sorts of movements irrespective of their manners.

Our data also shows that in the least prototypical boundary-crossing scene (i.e., the window scene) no trade-off between manner constructions and path constructions has been recorded for either group. When L1 speakers have not opted for $\left[\mathrm{V}_{\mathrm{M}}+\right.$ out $]$ constructions, they used $\left[\mathrm{V}_{\mathrm{M}}+\right.$ off $]$ constructions (e.g., 'fell off the window') instead. These findings are significant because they show a strong association between the expression of boundary-crossing and how prototypical a boundary-crossing scene is - an observation that the literature on motion event description and second language learning has hardly documented.

\section{Discussion}

Although we see our findings to be original in terms of the above, we also judge them to be in line with the overall conclusions reached by Alonso (2011), Larrañaga et al. (2011), and Wu (2011) for motion event description, as well as that of Schmiedtovà (2011) for differences in the expression of aspect between German and English. L1 TfS habits remain a challenge for L2 speakers even after many years of TL exposure and practice. Contra to what Ellis and Ferreira-Junior (2009) claim, our findings suggest that the frequency of exposure to target constructions does not necessarily promote learning and entrenchment. The $\left[\mathrm{V}_{\mathrm{M}}+\right.$ out $]$ construction is as salient in the expression of spatial boundaries in colloquial English as the use of versions of 'enter,' and 'exit' is in Spanish (Hoiting\&Slobin, 1994; Alonso, 2011). Despite this, and with the exception of participant [L], the remaining twelve L2 participants showed L1tuned TfS habits. This finding suggests that the frequency of target constructions (i.e., $\left[\mathrm{V}_{\mathrm{M}}+\right.$ out $]$ ) does not necessarily lead to noticing and learning. Participant [L]has achieved partial success in that she has used $\left[\mathrm{V}_{\mathrm{M}}+\right.$ out] constructions to describe boundary-crossing in the jar scene and the window scene but a $\left[\mathrm{V}_{\mathrm{P}}+\right.$ out] construction to describe the emergence of the owl from the hole.

We can tentatively explain the relative success of participant $[\mathrm{L}]$ as follows. A post-narrative interview with [L] reveals that the participant has lived in the UK for more than six years. [L]has married a Portuguese who also has been living in the UK for over ten years, and they have a five-year-old British born child. While the case of [L] suggests exposure to authentic language use may prove beneficial for some learners, the evidence reported on here also suggests that living for a short period in the host country is not enough. Several participants in this data have lived in either the UK or USA to complete their doctoral thesis, and yet, they did not show target-like TfS behaviors in this study. This suggestion goes contra to that of Song et al. (2016, p.14) who claim that studying a TL in the host country even for a short period is impactful:

\footnotetext{
${ }^{9}$ Despite the lack of multivariate normality of the measures, we consider the MANOVA analysis to be robust enough because the groups are balanced in terms of sample size between the measures (i.e., 13 participants each). Hence why the analysis of the MANOVA using the Pillai's Trace parameter is justified as per Field, Miles, \& Field (2012).
} 
[E]ven a short study abroad experience can bridge the gap between getting right most of the time versus getting right all of the time. It is not surprising that study abroad has such an impact, since this type of experience exposes a learner to massive amounts of input from native speakers who provide models of the appropriate linguistic structure.

While the conclusions reached by Song et al. seem to clash with ours, it is important to note the following caveat. It is generally documented that S-language speakers learning a V-language find it easier to learn target-like construction than V-language speakers learning S-languages (e.g.,AntonijevićandBerthaud, 2009; Stam,2010;Larrañagaetal., 2011). Song et al. (2016, p.13) remark:

[T] he lack of boundary crossing path prepositions forces the frequent use of path verbs [...]. Thus, when encountering boundary crossing events in their L2, English speaking L2 learners cannot use their L1 bias to attempt direct, word-to-word translations. Instead, they would be forced to choose an appropriate Spanish verb a path verb - to convey the meaning.

The consensus in the literature, therefore, suggests that V-language learners of English face an array of manner verbs and spatial particles that do not have one-to-one mappings in their L1s. However, this is not the difficulty the L2 participants in this study have been dealing with. To achieve target-like performances, the L2 speakers needed to know manner verbs like 'jump, 'fly,' 'fall,' and the boundary-crossing preposition 'out'. The evidence has reported that this was the case. The L2 data is replete with these lexemes. ${ }^{10}$ Consequently, the learning obstacle here is not lexical but constructional. The L2 speakers did not concatenate manner verbs with 'out' in single syntactic units to describe the scenes in question. L1-tuned habits, therefore, have remained pervasive for these advanced L2 speakers.

So, why were the L2 learners of English in this study unable to 'unlearn' their TfS habits despite many years of TLexposure?

Our study is not explicitly designed to address this question. However, insights from literature can be instructive. As such, following an examination of data collected from English learners of Spanish, Larrañaga et al. (2011) have reported their participants were not successful in learning target-like constructions. They claim that this relative 'failure' is because non-target-like motion event descriptions are usually not classified as "serious mistakes" in language classrooms (Larrañaga et al., 2011, pp. 134-135). They further propose that L1-influenced constructions continue to persist in the L2 TfS behavior because there is nothing in the input that informs otherwise. In other words, English speakers of Spanish continue to use communicatively off-target constructions like 'go out' or 'got out'because there is no evidence that these constructions are grammatically wrong.

Equally, Schmiedtovà (2011, p. 141) asserts that constructions that refer to conceptual knowledge which has preferential rather than absolute values are generally difficult to learn. To put it differently, alternative constructions that marginally express the same conceptual knowledge end up being accepted as alternate modes of expression of the same phenomenonbecause they are not usually judged ungrammatical:

Conceptual knowledge of any kind is the most complex domain to be acquired in a second language [...]. This type of knowledge usually does not follow patterns of formal but rather distributional accuracy; conceptual knowledge is a matter of preferences, which unlike grammatical features such as gender assignment do not mutually exclude each other, but rather co-exist in the same system.(Schmiedtovà, 2011, p. 141)

Based on Alonso's and Schmiedtovà's proposals, we can tentatively say that unlearning L1 TfS habits are likely to prove difficult if a semantic domain finds a learning environment in which:

a. There is an absence of evidence in the input to point out the ungrammaticality of acceptable but off-target L2 constructions.

b. There is a mutual tolerance of the L1-tuned constructions and the L2-target constructions when in the act of TfS. c. Non-target like constructions are usually not classified as 'serious mistakes,'particularly, in language classrooms.

\section{Conclusion}

That L1 TfS habits inhibit L2 learning at beginner, and intermediate levels are uncontested. What is still a matter of debate is whether this influence is equally pervasive at advanced levels of L2 learning as well. This study has engaged this topicconcerning the description of boundary crossing events in English. The evidence corroborates that L2 speakers of English have not unlearned their L1-tuned TfS habits even after many years of target language exposure and use. This finding is in line with those of Gass\& Mackey (2002) and Slabakova (2015) in that points to linguistic phenomena where input frequency is not sufficient to optimize learning.

\footnotetext{
${ }^{10}$ Recall 'out' has surfaced 66 times in the overall narrative of the L2 as opposed to 60 in the L1. 58
} 
Motion event constructions are cases in point precisely because these constructions tend to be tolerated by both Sframed and V-farmed language speakersregarding their grammatical accuracy but are considered off-target only on distributional grounds. Our findings encourage the conclusion that TfS about a conceptual domain like motion will remain a challenge for $\mathrm{V}$-language learners if targeted instructionsare not readily available.

\section{Limitations to This Study and Guidance for Future Research.}

A cautionary note about the generalizability of our findings must be exercised. First, it may be argued that our L2 sample (i.e., 13 participants) is too small to be generalizable to all L2 English learners whose L1 is Arabic. Second, according to one anonymous reviewer, the L1 deterministic conclusions obtained from only three boundary-crossing scenes cannot be generalizable with a reasonable degree of confidence. The reviewer has suggested that, it would be "more informative to compare narrations of boundary-crossing and non-boundary-crossing events to see how English L1, L2, and also Arabic L1 speakers varied their descriptions of these two types of motion events." While we acknowledge the potential contribution of this proposal to the existing TfSliterature, we believe the suggested research aims at a broader goal than what this study has set out to achieve. Precisely, our specific research goal was to report on data that showed advanced L2 English speakers differ from L1 English speakers in the way they describe manner versus path of motion in boundary crossing situations. Our data strongly argues that our L2 English participants have not moved in the direction of English lexicalization biases from the patterns typical of their L1. We are not claiming this conclusion is necessarily generalizable to semantic domains other than the description of motion in boundarycrossing situations. We leave it to future researchers to determine whether the same effects may obtain in other semantic domains (e.g., CAUSATION).

\section{References}

Antonijević,S., \&Berthaud, S.(2009).Verbsofmotionandsentence productioninsecondlanguage.InM. A. Elliott, S. Antonijević, S. Berthaud,P.Mulcahy,B.Bargary,C. Martyn, \&H.Schmidt(Eds.),FechnerDay2009: Proceedingsofthe

$25^{\text {th }}$ AnnualMeetingoftheInternationalSocietyforPsychophysics.Galway,Ireland:TheInternational SocietyforPsychophysics.

Alonso, R. A. (2011). The translation ofmotion events from Spanish into English: A cross-linguistic perspective.Perspectives: Studies in Translatology,19, 353-366.

Berman, R. A., \&Slobin, D. I., (Eds.). (1994). Relating Events in Narrative: A Cross-linguisticDevelopmental Study. Hillsdale, NJ: Erlbaum.

Cadierno, T. (2004). Expressing motionevents in a second language: A cognitive typological perspective. In M. Achard and S. Niemeier (Eds.),Cognitive Linguistics, Second Language Acquisition, and Foreign LanguageTeaching (pp. 13-49). Berlin: Walter de Gruyter.

Cadierno, T. (2010). Motion in Danish as asecondlanguage: Does the learner's L1 make a difference? In H. ZhaoHong and T. Cadierno (Eds.) LinguisticRelativity in SLA: Thinking for Speaking (pp. 1-33). Bristol: Multilingual Matters.

Cadierno, T., \& Ruiz, L. (2006). Motionevents in Spanish L2 acquisition. Annual Review ofCognitive Linguistics, 4, 183-216.

Cifuentez-Férez, P., \&Gentner, D. (2006). Naming motion events in Spanish and English. Cognitive Linguistics, 4, 443- 462.

Collins, L.,Trofimovich, P., White, J., Cardoso, W., \& Horst, M. (2009). Some input of theeasy/difficult grammar question: An empirical study. The Modern Language Journal, 93, 329-335.

Ellis, N. (2002). Frequency effects in language processing: A review with implications for theories of implicit and explicit language acquisition. SSLA, 24, 143-188.

Ellis, N., \&Ferreira-Junior, F.(2009). Construction learning as a function of frequency, frequency distribution, and function. The Modern Language Journal,93, 370-385

Ibarretxe-Antuñano, I. (2004). Motion events in Basque narratives. In S. Strömqvist\& L. Verhoeven (Eds.),Relating Events in Narrative:Typological and Contextual Perspectives, (pp. 89-112). Hillsdale, NJ: Erlbaum.

Feist, M. (2015). Minding your manners: Linguistic relativity in motion. Linguagemem(Dis)curso, 3, 591-602.

Gass, S. M., \&Mackey, A. (2002).Frequency effects and second language acquisition. In: Studies in Second Language Acquisition, 24(2),249-260

Larrañaga, P., Treffers-Dallers, J., Tidball, F., \& Ortega, M.G. (2011). L1 transfer in theacquisition of manner and path in Spanish by native speakers of English.International Journal of Bilingualism,14,117-138. 
Louhichi, I. (2015). The Motionisation of Verbs: A Contrastive Study of Thinking-for-Speaking in English and Tunisian Arabic. (Unpublished doctoral dissertation). Sussex University, Brighton.

Mayer, M. (1969). Frog, where are you? New York:Dial Books.

Loucks, J., \&Pederson, P. 2011. Linguistic and non-linguistic categorization of complex motion events. In Jürgen Bohnemeyer and Eric Pederson (Eds.), Event Representation in Language and Cognition, 108-133. Cambridge: Cambridge University Press.

Louhichi, I. (2018). The description of motion in Tunisian Arabic: A thinking-for-speaking approach. Sino-US English Teaching, 15(7), 346-36.MariñaTragas (http://marinatrigas.blogspot.com/2017/).

Özçalişkan, Ş. (2015). Ways of crossing aspatial boundary in typologically distinct languages. Applied Linguistics, 36, 485-508.

Paquot, M. (2017). L1 frequency in foreign language acquisition: Recurrent word combinations in French and Spanish EFL learner writing. Second language Research, 33, 13-32.

Rosch, E., Mervis, C.B., Gray, W.D., Johnson, D.M., \&Boyes-Braem, P. (1976). Basic objects in natural categories.Cognitive Psychology, 8, 382-439.

Schmiedtovà, B. (2011). Do L2 speakersthink in the L1 when speaking in the L2?VIAL, 8,139-179.

Slabakova, R. (2015). The effect of construction frequency and native transfer on second language knowledge of the syntax-discourse interface. Applied Linguistics, 36, 671-699.

Slobin, D. I. (1996a). Two ways to travel:Verbs of motion in English and Spanish. In M. Shibatani\& A. S.Thomson (Eds.),Grammatical Constructions: Their Form and Meaning (pp. 195-220). Oxford: Oxford University Press.

Slobin, D. I. (1996b). From "thought andlanguage" to "thinking for speaking". In: J. J. Gumperz\&S. C. Levinson (Eds.), Rethinking Linguistic Relativity (pp. 70-96).Cambridge: Cambridge University Press.

Slobin, D. I. (2000). Verbalized events: Adynamic approach to linguistic relativity and Determinism. In S. Niemeier\& R. Dirven (Eds.),Evidence forLinguistic Relativity (pp.107-138). Amsterdam: John Benjamins.

Slobin, D. I. (2004). The many ways to search for a frog. In S. Strömqvist\& L. Verhoeven (Eds.), Relating Events in Narrative, Vol. 2: Typological and Contextual Perspectives. Hillsdale, NJ: Erlbaum.

Slobin, D. I., \&Hoiting, N. (1994).Reference to movement in spoken and signed languages: Typological considerations.Proceedings of the 20th Annual Meeting of theBerkeley Linguistics Society: General Session Dedicated to the Contributions of Charles Fillmore(pp. 487-503).

Slobin, D.I., Ibarretxe-Antuñano I., Kopecka A., \&Majid A. (2014). Manners of human gait: A crosslinguistic eventnaming study. Cognitive Linguistics, 25(4),701-741.

Song L., Pulverman R., Pepe, Ch., Golinkoff, R., \&Hirsh-Pasek, K. (2016). Does the owl fly out of the tree or does the owl exit the tree flying? How L2 learners overcome their L1 lexicalization bias. Language Learning Development. HHS Public Access. Accessed online 8/25/2018.

Stam, G. A. (2010). Can an L2 speaker'spatterns of thinking for speaking change? In H. ZhaoHong\&T. Cadierno (Eds.),Linguistic Relativity in SLA: Thinking for Speaking (pp. 59-3). Bristol: Multilingual Matters.

Talmy, L. (1985). Lexicalization patterns:Semantic structure in lexical forms. InT. Shopen(Ed.),Language Typology and Syntactic Description, Vol. III:Grammatical Categories and the Lexicon (pp. 56-149). Cambridge: Cambridge University Press.

$\mathrm{Wu}, \mathrm{S}$. (2010). Learning to express motionevents in an L2: The case of Chinese directional complements.Language Learning, 61, 414-454.

Zlatev, J., \&Yankglang P. (2004). A thirdway to travel: The place of Thai in motion Typology. In S. Strömqvist\& L. Verhoeven (Eds.),Relating Events in Narrative: Typological and Contextual Perspectives (pp. 159-190). Hillsdale, NJ: Erlbaum

Zlatev, J., Blomberg, J., \& David, C. (2010). Translocation, language and the categorization of experience. In V. Evans \& P. Chilton (Eds.),Language, Cognition, and Space: The State of the Arts and New Directions (pp. 389-418). London: Equinox. 


\section{Appendices:}

Appendix 1:L1British EnglishParticipants

\begin{tabular}{|l|l|l|l|}
\hline Subjectcodes & Occupation & Age & Nationality \\
\hline$[$ A-E-F] & Teacher & 41 & British \\
\hline$[$ B-E-F] & Teacher & 33 & British \\
\hline$[$ C-E-F] & Teacher & 40 & British \\
\hline$[$ D-E-F] & Student & 22 & British \\
\hline$[$ E-E-F] & Musician(Busker) & 33 & British \\
\hline$[$ F-E-M] & Musician(Busker) & 46 & British \\
\hline$[$ G-E-F] & Teacher & 32 & British \\
\hline$[$ H-E-M] & Teacher & 33 & British \\
\hline$[$ I-E-M] & Artist & 48 & British \\
\hline$[$ J-E-M] & Teacher & 55 & British \\
\hline$[$ K-E-F] & Teacher & 30 & British \\
\hline$[$ L-E-F] & Editor & 40 & British \\
\hline$[$ M-E-F] & TeachingAssistant & 35 & British \\
\hline & & & \\
\hline
\end{tabular}

Appendix 2:L2Participants

\begin{tabular}{|c|c|c|c|}
\hline $\begin{array}{l}\text { Subject } \\
\text { ID }\end{array}$ & $\begin{array}{l}\text { Qualificationsandareaofexperti } \\
\text { se }\end{array}$ & TeachingExperience(years) & LengthofstayintheUK/US \\
\hline$[\mathrm{A}-\mathrm{T}-\mathrm{M}]$ & Tutorinreadingandreadingskills & 7 & 1 month \\
\hline$[\mathrm{B}-\mathrm{T}-\mathrm{M}]$ & Lecturerinliterature & 17 & $\begin{array}{l}\text { 1yearand2months+regulartripstoUKduri } \\
\text { ngthesummerholidays }\end{array}$ \\
\hline$[\mathrm{C}-\mathrm{T}-\mathrm{M}]$ & $\begin{array}{l}\text { Tutoringrammar and reading } \\
\text { Comprehension }\end{array}$ & 25 & 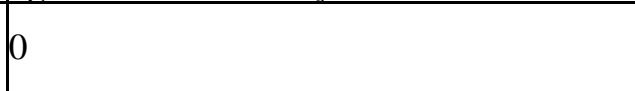 \\
\hline$[\mathrm{D}-\mathrm{T}-\mathrm{M}]$ & $\begin{array}{l}\text { Tutoringrammarand } \\
\text { Morphology }\end{array}$ & 13 & 0 \\
\hline [E-T-M] & Lecturerinlinguistics & 20 & 4.5years(onandoff) \\
\hline$[\mathrm{F}-\mathrm{T}-\mathrm{M}]$ & TutorinbusinessEnglish & 11 & 1 month \\
\hline$[\mathrm{G}-\mathrm{T}-\mathrm{M}]$ & $\begin{array}{l}\text { Tutorofgrammarand } \\
\text { Reading comprehension }\end{array}$ & 7 & 0 \\
\hline$[\mathrm{H}-\mathrm{T}-\mathrm{M}]$ & Lecturerinliterature & 10 & $\begin{array}{l}2 \text { monthsin the UK } \\
2 \text { monthsin the USA }\end{array}$ \\
\hline$[\mathrm{I}-\mathrm{T}-\mathrm{M}]$ & $\begin{array}{l}\text { Tutorinlanguageskillsandtranslati } \\
\text { on }\end{array}$ & 17 & 1yearandtwomonths \\
\hline$[\mathrm{J}-\mathrm{T}-\mathrm{M}]$ & Tutorinlinguistics & 3 & 0 \\
\hline$[\mathrm{K}-\mathrm{T}-\mathrm{M}]$ & Lecturerinliterature & 7 & 0 \\
\hline$[\mathrm{L}-\mathrm{T}-\mathrm{M}]$ & Lecturerinlinguistics & 6 & 6years \\
\hline$[\mathrm{M}-\mathrm{T}-\mathrm{F}]$ & Tutor in cultural studies & 16 & 2 months \\
\hline
\end{tabular}


Appendix 3: L1 responses (The jar scene)

\begin{tabular}{|c|c|c|c|}
\hline Sub/ID & Verbs & Examples & Frequency \\
\hline $\begin{array}{l}{[\mathrm{A}-\mathrm{E}-\mathrm{F} / 12+13-02]} \\
{[\mathrm{B}-\mathrm{E}-\mathrm{F} / 04+05-02]} \\
{[\mathrm{G}-\mathrm{E}-\mathrm{F} / 05-02]} \\
{[\mathrm{M}-\mathrm{E}-\mathrm{M} / 05+06-02]}\end{array}$ & $\begin{array}{l}\text { creep } \\
\text { out }\end{array}$ & The frog decided to escape from the jar, and he quietly crept out. & 4 \\
\hline$[\mathrm{C}-\mathrm{E}-\mathrm{F} / 14+15-02]$ & $\begin{array}{l}\text { sneak } \\
\text { out }\end{array}$ & $\begin{array}{l}\text { The frog sees Callum is a sleep, and decides he's gonnasneakout the } \\
\text { jar. }\end{array}$ & 1 \\
\hline $\begin{array}{l}{[\mathrm{D}-\mathrm{E}-\mathrm{F} / 06+07-02]} \\
{[\mathrm{L}-\mathrm{E}-\mathrm{F} / 08+09-02]} \\
{[\mathrm{K}-\mathrm{E}-\mathrm{F} / 05+06-02]} \\
{[\mathrm{F}-\mathrm{E}-\mathrm{M} / 06+07-02]}\end{array}$ & $\begin{array}{l}\text { climb } \\
\text { out }\end{array}$ & $\begin{array}{l}\text { During the night, the frog decided he wanted to go. So, } \\
\text { heclimbedout of the window. }\end{array}$ & 4 \\
\hline [E-E-F/09+10-02] & escape & He gets up, and he escapesfrom the jar. & 1 \\
\hline$[\mathrm{H}-\mathrm{E}-\mathrm{M} / 06+07-02]$ & $\begin{array}{l}\text { leap } \\
\text { out }\end{array}$ & The frog leaped out the jar and run off into the night. & 1 \\
\hline$[\mathrm{I}-\mathrm{E}-\mathrm{M} / 03+04+05-02]$ & be off & $\begin{array}{l}\text { During the night, the little frog thought "that twat didn't put the lid } \\
\text { on!" Bag this!Am off. }\end{array}$ & 1 \\
\hline$[\mathrm{J}-\mathrm{E}-\mathrm{F} / 05+06-02]$ & $\begin{array}{l}\text { jump } \\
\text { out }\end{array}$ & $\begin{array}{l}\text { Whilst Freddy slept soundly, the little frog jumped out of the jar and } \\
\text { disappeared. }\end{array}$ & 1 \\
\hline
\end{tabular}

Appendix 4: L2 responses (The jar scene)

\begin{tabular}{|c|c|c|c|}
\hline Subject and data ID & Constructions & Examples & Frequency \\
\hline $\begin{array}{l}\text { A-T-M/07+08+09-02] } \\
{[\mathrm{D}-\mathrm{T}-\mathrm{M} / 07+08+09-02]} \\
{[\mathrm{E}-\mathrm{T}-\mathrm{M} / 07+08-02]} \\
{[\mathrm{G}-\mathrm{T}-\mathrm{M} / 07+08-02]} \\
{[\mathrm{K}-\mathrm{T}-\mathrm{M} / 10+11-02]} \\
{[\mathrm{M}-\mathrm{T}-\mathrm{M} / 07+08-02]}\end{array}$ & got out & $\begin{array}{l}\text { At night, when he was sleeping, the frog got out of the } \\
\text { container } \text { of the jar\} and run away. } \\
\text { While the boy was sleeping, the frog managed to getout of } \\
\text { the bowl and went way. }\end{array}$ & $\begin{array}{lll}1 & j\end{array}$ \\
\hline [C-T-M/05+06-02] & leap out & The frog leapedout of the jar and ran away. & 1 \\
\hline$[\mathrm{J}-\mathrm{T}-\mathrm{F} / 09+10-02]$ & creep out & Elvis creptout of the bottle and escaped. & 1 \\
\hline$[\mathrm{L}-\mathrm{T}-\mathrm{F} / 15+16-02]$ & jump out & The froggy took the opportunity to jumpoutof the jar. & 1 \\
\hline $\begin{array}{l}{[\mathrm{B}-\mathrm{T}-} \\
\mathrm{M} / 14+15+16+17+18-02- \\
03]\end{array}$ & avoidance & $\begin{array}{l}\text { One night, Johnny and Sandy went to bed, and they left } \\
\text { Jumpy in her water ball \{sleeping for the night\}. The next } \\
\text { morning, both of them woke up and the water ball was } \\
\text { empty }\end{array}$ & 4 \\
\hline
\end{tabular}

Note: Respondent [B-T-M] exhibits a case of avoidance where he overlooked the crossing of the boundary. The other three participants have used constructions like escape or run away as avoidance strategies. 